Rom A. Stevens MD, Paul J. Lineberry MD, Thomas J. Arcario MD, Glenn S. Bacon Do, Larry W. Cress MD

\title{
Epidural anaesthesia attenuates the catecholamine response to hypoventilation
}

The effect of a high epidural block on the catecholamine response to hypoventilation was studied in six unanaesthetized dogs given intravenous sufentanil (I5 $\left.\mu \mathrm{g} \cdot \mathrm{kg}^{-1}\right)$. Sufentanil alone resulted in a increase of norepinephrine (NE) concentration from $108 \pm 73 \mathrm{pg} \cdot \mathrm{ml}^{-1} 10843 \pm 399 \mathrm{pg} \cdot \mathrm{ml}^{-1}$ and epinephrine (E) from $279 \pm 80 \mathrm{pg} \cdot \mathrm{ml}^{-1}$ to $2010 \pm 1416$ $\mathrm{pg} \cdot \mathrm{ml}^{-1}$. At least one week later, an epidural block to $T$, was achieved using 8-10 ml, two per cent lidocaine. Plasma $N E$ and $E$ decreased after $E A$ to about 50 per cent of resting baseline measurements. The addition of sufentanil increased $N E$ and $E$ levels to reach approximately the resting base-line levels. In all dogs intravenous sufentanil resulted in bradypnoea, bradycardia, hypoxaemia, and hypercarbia. Intravenous lidocaine infusions had no significant effect on plasma catecholamine levels when plasma lidocaine levels ranged from $1.7 \mu \mathrm{g} \cdot \mathrm{ml}^{-1}$ to 5.3 $\mu \mathrm{g} \cdot \mathrm{ml}^{-1}$. We conclude that a high two per cent lidocaine epidural block attenuates the catecholamine response to hypoventilation in dogs, but the persistence of baseline plasma levels of $N E$ and $E$ suggests that the efferent sympathetic block by high $E A$ is incomplete.

L'effet d'un bloc épidural haut sur la réponse des catécholamines à l'hypoventilation a été étudié sur six chiens non anesthésiés ayant reçu du sufentanil intraveineux $\left(15 \mu \mathrm{g} \cdot \mathrm{kg}^{-1}\right)$.

\section{Key words}

ANAESTHETIC TECHNIQUES: epidural;

ANAESTHETICS, LOCAL: lidocaine;

ANAESTHETICS INTRA VENOUS: sufentanil;

SYMPATHETIC NERVOUS SYSTEM: blockade, epinephrine, norepinephrine.

From the Departments of Anesthesiology, Uniformed Services University of the Health Sciences and the National Naval

Medical Center, Bethesda, Maryland 20814 USA.

Supported by USUHS Grant R08033.

These findings were presented at the 1989 Annual Meeting of the American Society of Anesthesiologists.

The views presented in this article are those of the authors and do not represent official policy of the U.S. Navy Medical Department or the Department of Defense.
Le sufentanil seul a amené une augmemtation de la norépine. phrine (NE) de $108 \pm 73 \mathrm{pg} \cdot \mathrm{ml}^{-1}$ à $843 \pm 399 \mathrm{pg} \cdot \mathrm{ml}^{-1}$ et des concentrations d'épinéphrine (E) de $279 \pm 80 \mathrm{pg} \cdot \mathrm{ml}^{-1}$ $2010 \pm 1416 \mathrm{pg} \cdot \mathrm{ml}^{-1}$. Au moins une semaine plus 1 ard, un bloc épidural a été acquis utilisant 8 a $10 \mathrm{ml}$ de deux pour cent de lidocaine. Les concentrations plasmatiques de NE et de $E$ ont diminuées après $E A d$ 'après peu près 50 pour cent des mesures de base. $L$ 'addition de sufentanil augmentant les niveaur de NE et de E pour atteindre approximativement les niveaux de base. Sur tous les chiens, le sufentanil intraveineux a amené une bradypnée, une bradycardie, une hypoxymie et une hypercarbie. Les infusions de lidocaine intraveineuses n'avaient aucun effet significatif sur les niveaux de catecholamine plasmatique quand le taux de lidocaine plasmatique s'étendait de 1.7 $\mu \mathrm{g} \cdot \mathrm{ml}^{-1}$ à $5.3 \mu \mathrm{g} \cdot \mathrm{ml}^{-1}$. On conclut qu'un bloc épidural haut avec deux pour cent de lidocaine atténue la réponse du catecholamine à l'hypoventilation chez les chiens et la persistance des niveaux plasmatiques de contrôle de NE et de $E$ suggère que le bloc sympathique efférent par un EA haut est incomplet.

Epidural anaesthesia (EA) has been shown to inhibit the catecholamine response to the surgical stress of lower abdominal surgery in patients receiving general anaesthesia.' This presumably occurs due to block of the nociceptive neural pathways by EA, due to blockade of the sympathetic efferent innervation of the adrenal medulla, or by a combination of these two. The exact mechanism, however, has not been established.

Physiological alterations, other than surgical pain, such as hypoxaemia and hypercarbia are potent stimuli of catecholamine release. ${ }^{2}$ How EA affects catecholamine release in response to physiological stresses is poorly understood. Since it is common in anaesthetic practice to sedate patients with opioids while undergoing surgery with an epidural or spinal block, these patients may be at some risk for hypoventilation, hypercarbia, and hypoxaemia. We designed this study in awake, trained dogs to determine how an extensive epidural block affects catecholamine release in response to hypoventilation. 


\section{Methods}

After obtaining permission for the study from our animal review board, we studied six female mongrel dogs (20-30 $\mathrm{kg}$ ) which were trained to lie unrestrained in the lateral decubitus position during the experiment. Carotid arteries in all animals had been chronically exteriorized into skin loops to allow for arterial access several months previously under a halothane anaesthetic. Before each experiment, the dogs were fasted for $12 \mathrm{hr}$ with free access to water.

With the animal lying in the lateral decubitus position on a padded table, cannulae were inserted into a peripheral vein and into an exteriorized carotid artery for arterial blood sampling and continuous blood pressure (BP) monitoring. Respiratory rate (RR) was measured via an air-filled rubber tube placed around the animal's thorax and altached via pressure tubing to a pressure transducer. The BP and RR were continuously recorded on a Gould 2-channel recorder (Instrument Systems Division, Gould, Inc., Cleveland, $\mathrm{OH}$ ). Heart Rate (HR) was read from the arterial wave form. The dogs were allowed to reach a calm resting state, judged by a RR of $<25 \mathrm{~min}^{-1}$, a HR of $<80$ $\min ^{-1}$, spontaneous eye closure, and the appearance of sinus arrhythmia seen in calm resting dogs. When the dog attained these criteria, the experiment was begun.

The first series of experiments were done without EA and were considered as controls. After the animal had reached the quiet resting state as defined above, $15 \mu \mathrm{g}$. $\mathrm{kg}^{-1}$ sufentanil were injected incrementally over 2-3 min intravenously to produce bradypnoea $\left(\mathrm{RR}<6 \mathrm{~min}^{-1}\right)$ and cyanosis. This dose of sufentanil does not produce unconsciousness in the dog. After five minutes, the opioid was reversed by intravenous naloxone $(0.4 \mathrm{mg})$ and the experiment terminated. Blood samples for arterial blood gas analysis (ABG's) and blood for NE and E determination were drawn prior to and five minutes after sufentanil injection (pre-sufentanil and post-sufentanil). The blood volume drawn for each sample was replaced with Ringer's lactate using a one to three ratio.

The second set of experiments was performed under EA. On the day preceding the experiment, an epidural catheter was placed percutaneously at the sixth lumbar interspace and advanced $3 \mathrm{~cm}$ into the epidural space under a brief thiopentone $\left(15 \mathrm{mg} \cdot \mathrm{kg}^{-1}\right)$ anaesthetic. Catheter placement was confirmed by fluoroscopy and the catheter was protected by a plaster cast. On the next day, cannulae and monitors were placed (vide supra) and after the animal had achieved a calm resting state, $8-10 \mathrm{ml}$, two per cent lidocaine (plain) were injected via the epidural catheter. An epidural block to at least $T_{1}$ was confirmed by paralysis of the hind legs, partial paralysis of the fore legs, diaphragmatic breathing, and paralysis of the membrana nictitans. ${ }^{7}$ When all the animals manifested the above signs of high epidural block, sufentanil 15 $\mu \mathrm{g} \cdot \mathrm{kg}^{-1}$ was injected intravenously which produced bradypnoea ( $R R<6 \mathrm{~min}^{-1}$ ) and cyanosis. Again, after five min of hypoventilation, the opioid effects were reversed with intravenous naloxone $(0.4 \mathrm{mg})$ and the experiment was terminated. At the end of the experiment all dogs still had evidence of a high epidural block. Blood samples for ABG's and plasma catecholamine determination were drawn in the calm resting state (pre-EA, pre-sufentanil), 20 min after epidural lidocaine injection (post-EA, pre-sufentanil), and five min after sufentanil injection (post-EA, post-sufentanil). Blood samples for plasma lidocaine determination were drawn 20 min after epidural lidocaine injection.

To determine the effect of plasma lidocaine concentrations alone on circulating plasma catecholamines, lidocaine was infused intravenously in these same animals at least one week later. With the animals monitored as before, and after reaching the calm, resting state, lidocaine was injected intravenously in a bolus $\left(1 \mathrm{mg} \cdot \mathrm{kg}^{-1}\right)$ and infused at $0.05 \mathrm{mg} \cdot \mathrm{kg}^{-1} \cdot \mathrm{min}^{-1}$. After $30 \mathrm{~min}$, a second bolus was given $\left(1 \mathrm{mg} \cdot \mathrm{kg}^{-1}\right)$ and the infusion rate was increased to $\left.0.1 \mathrm{mg} \cdot \mathrm{kg}^{-1} \cdot \mathrm{min}^{-1}\right)$. After another 30 $\mathrm{min}$, a third bolus of lidocaine was given $\left(\mathrm{l} \mathrm{mg} \cdot \mathrm{kg}^{-1}\right)$ and the infusion rate was increased to $0.2 \mathrm{mg} \cdot \mathrm{kg}^{-1} \cdot \mathrm{min}^{-1}$. Arterial blood samples for plasma lidocaine, plasma catecholamine determination, and ABGs were drawn in the calm resting state (control), and immediately after

TABLE I Physiological variables with hypoventilation. $n=6$ (means \pm SD)

\begin{tabular}{|c|c|c|c|c|c|}
\hline & \multicolumn{2}{|l|}{ Control series } & \multicolumn{3}{|l|}{ Epidural series } \\
\hline & Baseline & Hypoventilation & Baseline & $E A$ & $\begin{array}{l}\text { EA+ } \\
\text { Hypoventilation }\end{array}$ \\
\hline HR (bpm) & $61.3 \pm 9.5$ & $42.3 \pm 6.3 *$ & $67.5 \pm 10.2$ & $100.0 \pm 13.8^{*}$ & $64.0 \pm 9.4 \dagger$ \\
\hline MAP $(\mathrm{mmHg})$ & $85.2 \pm 8.5$ & $108.9 \pm 19.2^{*}$ & $84.1 \pm 7.8$ & $84.7 \pm 17.2$ & $44.1 \pm 16.3^{* \dagger}$ \\
\hline $\operatorname{RR}(r / \mathrm{min})$ & $16.2 \pm 6.2$ & $3.2 \pm 2.4^{*}$ & $17.0 \pm 5.5$ & $14.2 \pm 6.0$ & $3.5 \pm 2.3 * \dagger$ \\
\hline $\mathrm{pH}$ & $7.39 \pm 0.02$ & $7.32 \pm 0.02^{*}$ & $7.39 \pm 0.02$ & $7.35 \pm 0.04 *$ & $7.27 \pm 0.03^{*+}$ \\
\hline $\mathrm{PaCO}_{2} \mathrm{mmHg}$ & $35.8 \pm 1.8$ & $43.7 \pm 3.7^{*}$ & $34.8 \pm 1.0$ & $37.6 \pm 5.4$ & $47.4 \pm 4.4 * \dagger$ \\
\hline $\mathrm{PaO}_{2} \mathrm{mmHg}$ & $91.0 \pm 4.2$ & $38.2 \pm 5.2^{*}$ & $95.3 \pm 5.2$ & $84.2 \pm 12.9$ & $33.8 \pm 7.5 * \dagger$ \\
\hline
\end{tabular}

$* P \leq 0.05$ vs baseline. $\dagger=P \leq 0.05$ vs EA. 


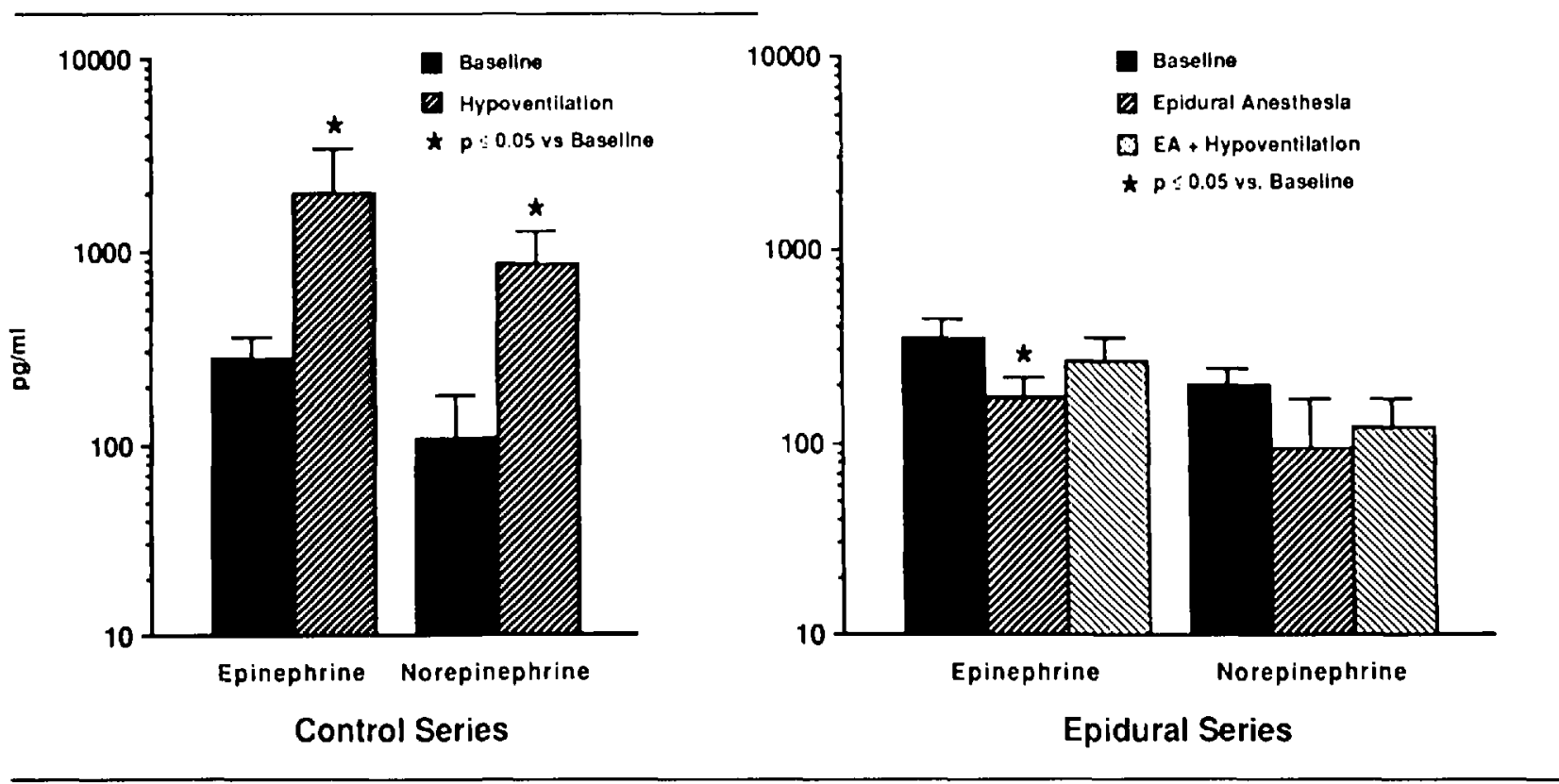

FIGURE I Plasma catecholamine concentrations in conscious dogs. Means \pm SD for $n=6$. Control series compares pre-sufentanil with post-sufentanil in dogs without an epidural block. Epidural series compares pre-EA, pre-sufentanil state, to post-EA, pre-sufentanil, and to post-EA, post-sufentanil.

each of the three 30-min lidocaine infusion periods (periods 1, 2, and 3).

Arterial blood samples were drawn in heparinized syringes and placed immediately on ice. The ABG analysis was done using an ABL-3 Acid-Base Laboratory (Radiometer, Copenhagen, Denmark). Blood samples for $\mathrm{NE}$ and $\mathrm{E}$ determination were centrifuged for ten minutes at $3000 \mathrm{rpm}$ at $4^{\circ} \mathrm{C}$. Glutathione and ethyleneglycoltetraacetic acid (EGTA) were added as an antioxidant and preservative, respectively. The samples were stored at $-70^{\circ} \mathrm{C}$ until analysis. Catecholamine analysis was done using high performance liquid chromatography (HPLC) using electrochemical detection and an internal standard. ${ }^{8}$ Limits of sensitivity were approximately $20 \mathrm{pg} \cdot \mathrm{ml}^{-1}$ for $\mathrm{NE}$ and $\mathrm{E}$. Plasma lidocaine was determined by a fluorescence polarization method (Therapeutic Drug Monitoring Systems, "TDX," Abbott Diagnostics, North Chicago, IL) with a sensitivity of $0.1 \mu \mathrm{g} \cdot \mathrm{ml}^{-1}$.

Values are reported as means \pm SD. The data were analyzed using an analysis of variance for multiple comparisons and where necessary, the Scheffe's test for paired data. Statistical significance was assumed at $P<$ 0.05 .

\section{Results}

\section{Effects of sufentanil alone}

In the control series (without EA), the injection of 15 $\mu \mathrm{g} \cdot \mathrm{kg}^{-1}$ sufentanil resulted in an increase in MAP, bradycardia, bradypnoea, severe hypoxaemia, and mild respiratory acidosis in all dogs (see Table I). Measurement of plasma catecholamine levels showed ten-fold increase in both NE and E concentration (Figure 1).

\section{Effects of epidural anaesthesia}

All dogs demonstrated signs of an epidural block to at least $T_{1}$. Most dogs were not able to raise their heads off the laboratory table by ten minutes after epidural lidocaine injection. Epidural block alone resulted in no change in MAP, an increase in HR and a slight decrease in $\mathrm{pHa}$ (not clinically significant). No significant changes in RR, $\mathrm{PCO}_{2}$, or $\mathrm{PO}_{2}$ were detected (Table I). Baseline measurements of $N E$ and $E$ were not statistically different between the Control Series and the Epidural Series. After EA, plasma catecholamine levels decreased to about 50 per cent of baseline values. This decrease was statistically significant for $\mathrm{E}$ but not for NE (Figure 1).

\section{Effects of epidural anaesthesia and sufentanil}

Injection of sufentanil in dogs with EA resulted in a decrease in MAP, HR, bradypnoea, severe hypoxaemia, and respiratory acidosis. Plasma NE and $E$ levels increased slightly compared with the post-EA, presufentanil state, and were not statistically different from resting baseline levels (pre-EA) (Figure 1). Plasma lidocaine levels $20 \mathrm{~min}$ after epidural lidocaine injection, at the time when sufentanil was injected, were $1.8 \pm 0.3$ $\mu \mathrm{g} \cdot \mathrm{ml}^{-1}$. 


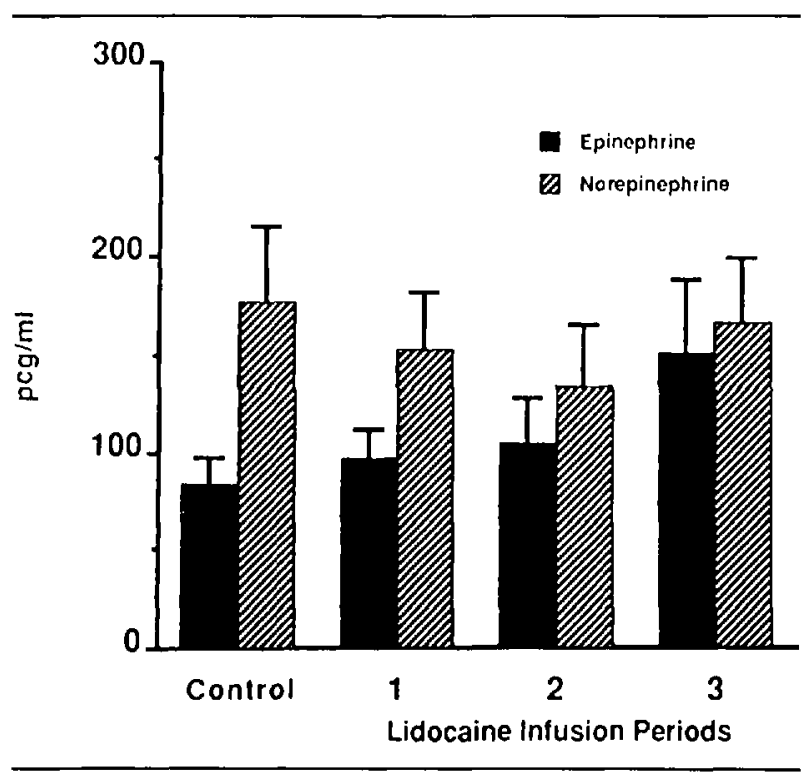

FIGURE 2 Plasma catecholamine levels in conscious dogs prior to and after 30-minute intravenous lidocaine infusion periods. Control samples were drawn just prior to start of infusions. Infusion periods 1 , 2 , and 3 represent $0.05,0.1$, and $0.2 \mathrm{mg} \cdot \mathrm{kg}^{-1} \cdot \mathrm{min}^{-1}$ infusions, respectively. Each infusion period was preceded by a bolus dose of 0.1 $\mathrm{mg} \cdot \mathrm{kg}^{-1}$ lidocaine. Levels for each infusion period were drawn at the end of the period, just prior to the next bolus dose of lidocaine.

\section{Effect of intravenous lidocaine infusion}

Intravenous infusion of lidocaine had no significant effect on the physiological variables measured (HR, MAP, RR, $\mathrm{pHa}, \mathrm{PO}_{2}$ or $\mathrm{PCO}_{2}$ ) even at the highest infusion rate, where all dogs manifested signs of early central nervous system (CNS) toxicity. Plasma lidocaine levels after the first, second, and third infusions were $1.7 \pm 0.3 \mu \mathrm{g} \cdot \mathrm{ml}^{-1}, 3.0$ $\pm 0.6 \mu \mathrm{g} \cdot \mathrm{ml}^{-1}$, and $5.3 \pm 1.2 \mu \mathrm{g} \cdot \mathrm{ml}^{-1}$ respectively. Although mean plasma $E$ levels tended to increase with increasing plasma lidocaine concentrations, this did not attain statistical significance. There was no significant change in plasma NE levels with increasing plasma lidocaine concentrations (Figure 2).

\section{Discussion}

Our results indicate that a high level of epidural block using two per cent lidocaine (plain) results in a moderate decrease in plasma NE and $E$ in awake unstressed dogs and attenuates the large increase in plasma catecholamines seen in hypoventilating dogs without EA. Plasma lidocaine levels at the time of catecholamine measurements were low (mean $1.8 \mu \mathrm{g} \cdot \mathrm{ml}^{-1}$ ). Additionally, subtoxic and toxic plasma lidocaine concentrations alone do not change circulating levels of NE and $E$ in awake dogs. Because of this, we feel that the effect of systemically absorbed lidocaine is unlikely to account for changes in plasma catecholamine levels seen after EA and after sufentanil in dogs with EA.

\section{Effect of EA on plasma catecholamines}

It is not surprising that an epidural block from $S_{5}-T_{1}$ produced a decrease in plasma catecholamine concentrations. Moderate decreases in plasma catecholamine levels have been reported in patients with epidural blocks ranging from $T_{10}-T_{4}^{5}$ and in patients with epidural blocks to $T_{4}{ }^{1}$ What is surprising is that despite EA to at least $T_{1}$, which should have produced a complete sympathectomy, $\mathrm{NE}$ and $\mathrm{E}$ levels post-EA were still 50 per cent of pre-EA measurements in our dogs. The adrenal medulla is innervated by sympathetic fibres originating from spinal segments $T_{4}-L_{2}$ in dogs ${ }^{6}$ and from $T_{6}-L_{2}$ in man. ${ }^{7}$ Norepinephrine is released from peripheral sympathetic nerve terminals throughout the body. The adrenal medulla which is the only source for $E$ release, also releases $N E$ into the circulation. ${ }^{8}$ Some intact sympathetic innervation to the adrenal medulla is apparently necessary for $E$ release to occur in dogs. As shown by Mills et al. in dogs, a total spinal block with $20 \mathrm{mg}$ of intrathecal tetracaine causes a decrease in $E$ and NE to barely detectable levels. ${ }^{9}$ Therefore, the persistence of circulating NE and E post-EA implies an incomplete block of the sympathetic efferent nerves.

\section{Degree of sympathectomy produced by $E A$}

It has long been assumed that the sympathetic fibres, due to their smaller diameter compared with motor and somato-sensory fibres, are blocked earlier and with lower concentrations of local anaesthetic. This is the basis of the differential spinal and epidural blocks. ${ }^{10} \mathrm{~A}$ corollary of this is that a sensory and motor block assures a sympathetic block. All of our dogs demonstrated motor block of the upper and lower extremities, and most dogs were not able to lift their heads from the table. Our results suggest that the presence of a motor block does not necessarily guarantee a complete sympathectomy.

Bromage has stated that the blockade produced by EA is seldom complete for motor and sensory fibres, certainly less so than that produced by spinal anaesthesia. " He suggested that the sympathetic efferent fibres may also be blocked incompletely during EA, particularly when using epinephrine-free local anaesthetic solutions. This could explain the increase in HR seen in our dogs after EA because of an incomplete block of the cardio-accelerator fibres, and explain as well the persistence of circulating $\mathrm{NE}$ and $\mathrm{E}$ levels in our dogs.

\section{Attenuation of the sympathoadrenal response to hypoventilation}

A recent study by Peters et al. ${ }^{12}$ showed that EA attenuates the cardiovascular response to hypoxaemia. They used an awake dog model very similar to ours, but produced hypoxaemia by decreasing the inspired $\mathrm{O}_{2}$ rather 
TABLE II Physiological variables during lidocaine infusions. $n=6$ (means \pm SD)

\begin{tabular}{|c|c|c|c|c|c|c|}
\hline \multirow[b]{2}{*}{ HR (bpm) } & Baseline & Lido I & \multicolumn{2}{|l|}{ Lido 2} & \multicolumn{2}{|l|}{ Lido 3} \\
\hline & $67.3 \pm 11.4$ & $68.7 \pm 7.6$ & 60 & \pm 10.8 & 72 & \pm 21.7 \\
\hline $\mathrm{RR}(\mathrm{r} / \mathrm{min})$ & $17.7 \pm 1.5$ & $17.3 \pm 1.6$ & 11 & \pm 2.4 & 10.3 & \pm 2.9 \\
\hline $\mathrm{MAP}(\mathrm{mmHg})$ & $96.3 \pm 11.5$ & $97.8 \pm 16.5$ & 95.5 & \pm 14.1 & 102.2 & \pm 19.1 \\
\hline $\mathrm{pH}$ & $7.41 \pm 0.03$ & $7.41 \pm 0.03$ & 7.41 & \pm 0.02 & 7.41 & \pm 0.02 \\
\hline $\mathrm{PCO}_{2}(\mathrm{mmHg})$ & $33.6 \pm 2.5$ & $33.4 \pm 3.4$ & 33.3 & \pm 2.9 & 33.3 & \pm 2.6 \\
\hline $\mathrm{PO}_{2}(\mathrm{mmHg})$ & $104.5 \pm 6.9$ & $109.5 \pm 7.2$ & 108.2 & \pm 6.1 & 112.5 & \pm 10.6 \\
\hline $\mathrm{LIDO}(\mathrm{mcg} / \mathrm{ml})$ & 一 & $1.7 \pm 0.3$ & 3.0 & $\pm 0.6^{*}$ & 5.3 & $\pm 1.2 * \dagger$ \\
\hline
\end{tabular}

* $P \leq 0.05$ vs Lido $1 . \dagger P \leq 0.05$ vs Lido 2 . There were no significant differences in physiologic parameters between baseline and any lidocaine infusion periods.

than by producing hypoventilation with an opioid. They also measured catecholamines as well as other vasoactive hormones (vasopressin and renin). Their findings agree with ours in that they found only a moderate decrease in $\mathrm{NE}$ and $\mathrm{E}$ despite an extensive epidural block. Although their dogs experienced a similar degree of hypoxaemia as in our experiments, their dogs hyperventilated as they became hypoxaemic so did not become hypercarbic. They did not see the large rise in plasma NE and $E$ that we found. This finding is probably due to the additional stress of hypercarbic acidosis in our dogs, as the combination of hypoxaemia and hypercarbemia is a more potent stimulus of catecholamine secretion than either stressor alone. ${ }^{2}$ Because they did not see a large increase in NE or $E$ in their unblocked hypoxaemic dogs, they could not evaluate the effect of EA on the catecholamine response to this physiological stress. We found that, in spite of an incomplete sympathetic block, EA inhibited the catecholamine response to marked hypoventilation. Apparently a sufficient percentage of sympathetic efferent fibres was blocked to inhibit the catecholamine response.

\section{Possible clinical relevance of the attenuation of the sympathoadrenal response by $E A$}

The clinical importance of our results is that a patient with a high epidural block who hypoventilates following over-sedation may not be able to mount a sympathoadrenal response to hypoventilation. Caplan et al. reported a series of 14 unexpected cardiac arrests with poor neurological outcomes in patients under spinal anesthaesia combined with intravenous sedation. ${ }^{13}$ In over half of the cases, bradycardia was the initial clue alerting the anaesthetist to the presence of a problem. Ephedrine (a relatively weak alpha and beta adrenergic agonist) and atropine were the first drugs given to treat the bradycardia and subsequent hypotension. The authors suggested that this poor outcome may have been due to the high sympathetic blockade making resuscitation efforts more difficult or perhaps contributing to the cardiac arrest. For example, Greene ${ }^{14}$ has pointed out that hypoxaemia and hypercarbia can cause significant vasodilation in the presence of sympathetic blockade. Reduced cardiac filling combined with unopposed vagal tone could lead to bradycardia, hypotension, and ultimately, cardiac arrest.

Our data provide a possible additional explanation for Caplan's findings, in that our dogs were unable to mount a catecholamine response to hypoventilation. It may be that the inability to mount a catecholamine response results in a poorer outcome or possibly interferes with resuscitation efforts. Perhaps a direct-acting catecholamine should be administered early to a patient with a high epidural (or spinal) block who develops bradycardia or hypotension. More laboratory research is needed to determine the most efficacious method of resuscitating animals with extensive epidural or spinal blocks.

\section{Acknowledgement}

The authors wish to thank Professor Sheila Muldoon for her kind assistance in the preparation of this manuscript.

\section{References}

1 Enquist A, Fog Moller F, Christensen $C$, Thode $J$. Influence of epidural anesthesia on the catecholamine and cyclic AMP response to surgery. Acta Anaesthesiol Scand 1980; 24: 17-21.

2 Rose EC, Althaus JA, Kaiser DL, Miller EB, Carey $R M$. Acute hypoxaemia and hypercarbia: increases plasma catecholamines in conscious dogs. Am J Physiol 1983; 245: H924-9.

3 Lebeaux MF. Experimental epidural anaesthesia in dogs with lignocaine and bupivacaine. Br J Anaesth 1973; 45: 549-5.

4 Causon RC, Carruthers ME. Measurement of catecholamines in biological fluids by high-performance liquid chromatography. J Chromatogr 1982; 229: 301-9.

5 Ecoffey C, Edouard A, Pruszynski W, Taly E, Samii $K$. Effects of epidural anesthesia on catecholanines, renin activity, and vasopressin changes induced by tilt in elderly men. Anesthesiology 1985; 62: 294-7. 
6 Cuminings $J F$. Thoracolumbar preganglionic neurons and adrenal innervations in the dog. Acta Anat (Basel) 1951; 13: 81-9.

7 Bonica JJ. Autonomic innervation of the viscera in relation to nerve block. Anesthesiology 1968; 29: $793-813$.

8 Ganong WF. Review of Medical Physiology, 9th ed., Los Altos. Lang Medical Publications, 1979; 279-81.

9 Mills CA, Flacke JW, Miller JD, Davis LJ, Bloor BC, Flacke WE. Cardiovascular effects of fentanyl reversal by naloxone at varying arterial carbon dioxide tensions in dogs. Anesth Analg 1988; 67: 703-6.

10 Winnie AP, Collins VJ. Differential neural blockade in pain syndromes of questionable etiology. Med Clin North Am 1968; 52: 123-9.

II Bromage PR. Epidural Analgesia. Philadelphia: Saunders Co, 1978, 350-I, 357-365.

12 Peters J, Kutkuhn B, Medert HA, Schlaghecke R, SchuelIler J, Arndt JO. Sympathetic blockade by epidural anesthesia attenuates the cardiovascular response to severe hypoxemia. Anesthesiology 1990; 72: 134-44.

13 Caplan RA, Ward RJ, Posner K, Cheney FW. Unexpected cardiac arrest during spinal anesthesia: a closed claims analysis of predisposing factors. Anesthesiology 1988; 68: 5-11.

14 Greene NM. Physiology of Spinal Anesthesia, 3rd ed. Baltimore: Williams and Wilkins, 1981; 75-6. 